Revista Complutense de Educación

ISSNe: 1988-2793

http://dx.doi.org/10.5209/RCED.61566

\title{
Identidad profesional docente
}

Autores: Isabel Cantón Mayo y Maurice Tardif (coords.)

Editorial: Narcea

Año de publicación: 2018

$N^{o}$ de páginas: 229

ISBN: 978-84-277-2396-2

Los autores Isabel Cantón Mayo y Maurice Tardif coordinan y elaboran una obra sobre Identidad Profesional Docente, en la que participan importantes autores internacionales especialistas en el tema. La obra está compuesta por 12 capítulos que abordan los objetivos planteados (en relación con la construcción, conocimiento y perspectiva comparativa multidisciplinar e internacional del tema) a través de un recorrido ágil y muy acertado sobre la construcción de la identidad docente desde diferentes perspectivas y un estudio de dicha identidad en diferentes colectivos, tales como profesores de primaria, secundaria y universidad.

El primer capítulo aporta una visión de la identidad docente desde la sociología planteando, asimismo, cuestiones sobre la evolución de dicho concepto en general y particularmente, en Canadá. Los autores ponen un marco de reflexión muy acertado, en el que afirman que la profesión docente atraviesa una etapa de cuestionamiento de la identidad, en la que está surgiendo lo que los autores denominan una identidad profesional con sufrimiento. Esta lectura nos permite ver como la identidad docente está influenciada por el contexto de escuela y sociedad en la que se inserta la labor profesional.

A continuación, se reflexiona sobre la relación entre Identidad Profesional y Calidad de la mano de uno de los co-coordinadores del presente libro. Por ello, en este capítulo se hace un exhaustivo recorrido por la literatura que trabaja la calidad y satisfacción del profesorado que nos lleva hasta un isomorfismo que nos permite medir la calidad de la identidad profesional.

Los autores del tercer capítulo profundizan en el concepto de identidad a través de la construcción de ésta en los primeros años del docente como profesional. Para ello, presentan los principales factores que representan la identidad profesional docente en los tres elementos que definen: personales, profesionales y contextuales. Muy relacionado con este capítulo se encuentra el siguiente, el cual estudia el paso de la identidad de estudiante a la de docente principiante. Para ello, analizan el saber "formal" como un componente fundamental para comprender la identidad, pero que se debe ver acompañado de una adaptación. De esta forma se explica la socialización profesional y construcción del yo en la transición hacia una nueva profesión.

En el quinto capítulo, el autor va más allá y se plantea la existencia de identidades, en plural. En concreto, identidad profesional, laboral y docente. El capítulo 
centra su discurso en la identidad laboral del profesorado, detallando los factores que la constituyen, sus componentes y concluyendo con su construcción y desarrollo.

Seguimos con una reflexión muy acertada sobre la incidencia de las políticas educativas en el desarrollo de la identidad profesional docente y las Comunidades Profesionales de Aprendizaje como elementos implicados en dicho desarrollo. En el capítulo se contrapone la construcción de la identidad profesional sustentada en los diseños de las políticas educativas y el desarrollo a partir del propio proyecto profesional del docente.

Cerrando esta primera parte de la obra en la que se asienta la reflexión y análisis de la Identidad Profesional Docente, no podía faltar un capítulo orientado a la construcción de la identidad en grupo. Los centros educativos son comunidades de aprendizaje y, por ende, el profesorado se encuentra en constante interacción entre sí. Favorecer una cultura grupal que impulse la creación de comunidades formativas de aprendizaje, permite orientar las acciones individuales y colectivas. Además, se presentan los resultados de un proyecto que identifica a los miembros de una organización y fortalece la cultura corporativa de forma que permita mejorar la construcción de la identidad docente.

A partir de este punto, los coordinadores centran la obra en la exposición de la identidad del profesorado según diferentes etapas educativas.

En primer lugar, la identidad del profesorado universitario. La universidad ha cambiado sus estructuras organizativas y académicas lo que ha provocado la modificación de la identidad de los profesorados. En este capítulo se hace una ágil y profunda reflexión sobre los dilemas a los que se enfrenta el profesorado universitario de cara a definir su identidad como docentes y define tres aspectos esenciales como son lo que somos como personas, lo que somos como docentes y lo que somos como miembro de un equipo.

En segundo lugar, la identidad del maestro de primaria y sus fases de desarrollo. La identidad se construye desde su formación inicial hasta su jubilación. En este capítulo se hace referencia a los cambios que acontecen a lo largo de estas etapas en la identidad concretamente del maestro de primaria. Se concluye que dicho desarrollo está en constante evolución en función de factores personales y sociales.

En tercer lugar, los autores del décimo capítulo, nos acercan a una situación real del profesorado de secundaria y a la muy bien definida como destrucción de la identidad. Para ello, hacen una magnífica reflexión sobre un reportaje de la televisión francesa en el que un periodista logra ser contratado como profesor sustituto de matemáticas.

A continuación, se sitúa un capítulo sobre la salud ocupacional del profesorado no universitario, un tema de gran actualidad e importancia. La identidad profesional también se ve marcada por las experiencias personales del docente, y su salud es uno de los aspectos más influyentes.

Se termina esta obra con un capítulo dedicado a la influencia de las políticas en la identidad docente. Estas políticas inciden en los planes de formación de los futuros docentes y por tanto en la identidad que conforman éstos.

La obra cierra sus páginas con un espacio de bibliografía muy amplia e interesante que aporta una mayor profundización a los diversos temas que se han tratado en el libro. Nos encontramos ante una obra muy destacable por el cuidado análisis que realizan cada uno de los autores participantes de los muchos factores que nos pueden ayudar a conformar el constructo de identidad profesional docente. En definitiva, es 
una obra recomendable para quien quiera abordar una reflexión profunda sobre el ser de un profesor en la actualidad o bien para quien quiera conocer de forma global el estudio de dicho concepto.

$\mathrm{M}^{\mathrm{a}}$ Aranzazu Carrasco Temiño Universidad Complutense de Madrid mcarrasco@ucm.es 